\title{
The effects of arbuscular mycorrhizal fungi and root interaction on the competition between Trifolium repens and Lolium perenne
}

\author{
Haiyan Ren ${ }^{\text {Corresp., }}{ }^{1}$, Tao Gao ${ }^{1}$, Jian Hu ${ }^{1}$, Gaowen Yang ${ }^{\text {Corresp. } 1}$ \\ ${ }^{1}$ College of Agro-grassland Science, Nanjing Agricultural University, Nanjing, China \\ Corresponding Authors: Haiyan Ren, Gaowen Yang \\ Email address: hren@njau.edu.cn, yanggw@njau.edu.cn
}

Understanding the factors that alter competitive interactions and coexistence between plants is a key issue in ecological research. A pot experiment was conducted to test effects of root interaction and arbuscular mycorrhizal fungi (AMF) inoculation on the interspecies competition between Trifolium repens and Lolium perenne under different proportions of mixed sowing by the combination treatment of two levels of AMF inoculation (inoculation and non- inoculation) and two levels of root interaction (root interaction and non- root interaction). Overall, the aboveground and belowground biomass of $T$. repens and $L$. perenne were not altered by AMF inoculation across planting ratios, probably because the fertile soil reduced the positive effect of AMF on plant growth. Both inter- and intraspecies root interaction significantly decreased the aboveground biomass of $T$. repens, but tended to increase the aboveground biomass of $L$. perenne across planting ratios, and thus peaked at the 4:4 polyculture. These results showed that $T$. repens competed poorly with $L$. perenne because of inter and intraspecies root interaction. Our results indicate that interspecies root interaction regulates the competitive ability of grass $L$. perenne and legume $T$. repens in mixtures and further makes great contribution for overyielding. Furthermore, AMF may not be involved in plant-plant interaction in fertile condition. 
The effects of arbuscular mycorrhizal fungi and root interaction on the competition

\section{between Trifolium repens and Lolium perenne}

Haiyan Ren ${ }^{1}$, Tao $\mathrm{Gao}^{1}$, Jian $\mathrm{Hu}^{1}$, Gaowen Yang ${ }^{1}$

1 College of Agro-grassland Science, Nanjing Agricultural University, Nanjing 210095, China

*Correspondence author. E-mail: yanggw@njau.edu.cn

A running headline: Arbuscular mycorrhizal fungi and root interaction effects 


\section{Abstract}

1 Understanding the factors that alter competitive interactions and coexistence between plants

2 is a key issue in ecological research. A pot experiment was conducted to test effects of root

3 interaction and arbuscular mycorrhizal fungi (AMF) inoculation on the interspecies competition

4 between Trifolium repens and Lolium perenne under different proportions of mixed sowing by

5 the combination treatment of two levels of AMF inoculation (inoculation and non- inoculation)

6 and two levels of root interaction (root interaction and non- root interaction). Overall, the

7 aboveground and belowground biomass of T. repens and L. perenne were not altered by AMF

8 inoculation across planting ratios, probably because the fertile soil reduced the positive effect of

9 AMF on plant growth. Both inter- and intraspecies root interaction significantly decreased the

10 aboveground biomass of $T$. repens, but tended to increase the aboveground biomass of $L$.

11 perenne across planting ratios, and thus peaked at the $4: 4$ polyculture. These results showed that

12 T. repens competed poorly with L. perenne because of inter and intraspecies root interaction. Our

results indicate that interspecies root interaction regulates the competitive ability of grass $L$.

perenne and legume $T$. repens in mixtures and further makes great contribution for overyielding.

Furthermore, AMF may not be involved in plant-plant interaction in fertile condition.

Introduction 
21 Plurispecific plant communities are usually more productive than monoculture, because the

diverse communities are expected to optimize available resources due to positive interspecific interactions and species niche complementarities (Loreau and Hector 2001, Hooper et al. 2005).

So far, modern coexistence theory and contemporary niche theory are most popular hypotheses for illustrating intra- and interspecific interactions (Letten et al. 2017). These studies mostly focused on aboveground interactions and less is known about the effect of root-root interaction among plants on plant-plant interaction.

Mixtures of legumes and non-legumes which have been widely used in mixed sowing pasture and agricultural intercropping system can achieve better performance in productivity and stability (Hebeisen et al. 1997, Sanderson et al. 2013, Li et al. 2016, Elgersma and Søegaard 2017, Wang et al. 2017). Their coexistence links to intra- and interspecific interactions (Letten et al. 2017, Ulrich et al. 2017). Legumes and non-legumes compete for light, water and soil nutrient resources and also compensate for physiological traits and nutrient distribution from each other (Schwinning and Parsons 1996, del Río et al. 2016).

Grass-clover mixtures of Lolium (grass) and Trifolium (legume) are considered as model system in agricultural and natural grassland ecosystems (Nyfeler et al. 2009). The persistence and stability of these two species mixed grassland depend on fertilizer type, growth period, outer press frequency and time (e.g. mowing) (Elgersma et al. 1998, Nassiri and Elgersma 1998, Elgersma et al. 2000). In addition, Cernoch and Houdek (1994) found that soil moisture had a strong effect on the nitrogen $(\mathrm{N})$ utilization of $T$. repens and L. perenne. L. perenne $\mathrm{N}$ absorption increased along with soil moisture and further enhanced its competitive ability, while $T$. repens 
42 displayed a weaker $\mathrm{N}$ response at a higher soil moisture. These studies more focused on

43 aboveground factors and water and nutrients utilization, less is done with regard to their root

44 interactions and soil microorganism effects.

45 Root interactions, including biological, physical and chemical interactions, occur between

46 plants. It was found that adding $\mathrm{N}$ fertilizer could enhance the competitive ability of L. perenne;

47 while adding phosphorous (P) fertilizer could enhance the competitive ability of $T$. repens in their mixtures (Dennis and Woledge 1987, Davidson and Robson 1990). Root exudates has been

49 shown to drive interspecific facilitation by enhancing nodulation and $\mathrm{N}_{2}$ fixation, and $\mathrm{N}$ fixed by

50 legumes can be transferred to grasses (Louarn et al. 2015, Li et al. 2016, Thilakarathna et al.

51 2016). However, whether root physical interactions will affect grass-clover interaction is still

52 unknown. Several studies found that L. perenne had a higher competitive ability than T.repens,

53 resulting from its fast growing root and a higher utilization efficiency in light (Luescher and

54 Jacquard 1991, Kleen et al. 2011). Thus, physical interactions between grass-clover may

55 increase their competition.

56 Arbuscular mycorrhizal fungi (AMF) are considered as key soil microorganisms and can

57 colonize 80\% terrestrial plants (Smith and Read 2008, Brundrett 2009). AMF can form

58 symbiotic associations with plants and affect interspecific interactions by enlarging nutrient

59 absorbing area of plant root systems, and further promote plant nutrient uptake and resistance to

60 stress (Smith and Read 2008). AMF acquire $\mathrm{N}$ from $\mathrm{N}$ sources and transfer some of this $\mathrm{N}$ to

61 their host plant (Hodge and Storer 2015). Wagg et al. (2011) found that in mixtures of $T$.

62 pratense and L. multiflorum, AMF could reduce their differences in competitive ability by 
enhancing the competitive power of T. pratense with its higher productivity. However, how do AMF, root and their interactions affect $T$. repens and L. perenne in their mixtures need to be further tested.

In this study, AMF inoculation and root physical interaction of $T$. repens and L. perenne among their different planting ratios were investigated. We hypothesize that (1) root physical interaction can increase competition between T. repens and L. perenne; (2) AMF inoculation can relax the effect of root physical interaction on competition. It would help us deeply understand their survival strategies and coexistence of legumes and grasses, and provide effective guide for pasture management.

\section{Materials and Methods}

\section{Experimental design}

We employed a full factorial design that consisted of combinations of five plant-competition treatments, two levels of AMF inoculation (+AMF and -AMF) and two levels of root interaction treatments (+Root and -Root). Individuals of T. repens $(\mathrm{T})$ and $L$. perenne $(\mathrm{L})$ were planted in the mixed ratios: 8:0, 6:2, 4:4, 2:6 and 0:8 (T8L0, T6L2, T4L4, T2L6 and T0L8, respectively) to simulate competition between these two species. There were 20 treatments in total with five replicates per treatment. To investigate the amount of nitrogen fixed by T. repens and potentially transferred to other plants, additional three replicates were added for T8L0, T6L2, T4L4 and T2L6 in both +AMF and -AMF treatments. We established 124 microcosms under greenhouse conditions in cylindrical containers (Fig. 1). Microcosm without root interaction was achieved by eight separated plant growth pillars in which plant individuals were planted respectively (Fig. 1a). 
84 Pillar was made of $25-\mu \mathrm{m}$ nylon mesh, which allowed AM mycelia access but not roots. Each

pillar contained soil mixture of $188 \mathrm{~g}$. The eight plant growth pillars were evenly located close to the container wall. In microcosm with root interaction, eight plant individuals were planted together and evenly spaced into the space between the container and root restriction pillar, which contained soil mixture of $1504 \mathrm{~g}(188 \mathrm{~g} * 8)$. Thus, the total growth space for the roots of the eight plants was the same in microcosms without root interaction and in microcosms with root interaction. The methods only tested the root physical interactions (root interaction in the following text) as roots also interact through their exudates, which cannot be avoided to go through the mesh we used in the experiment.

\section{Soil and inoculum preparation}

Each container was $15 \mathrm{~cm}$ in height and $19 \mathrm{~cm}$ in diameter and was filled with $5.88 \mathrm{~kg}$ sterilized (25 kGy $\gamma$-irradiation) soil mixture of field soil, sand and grass peat $(5: 4: 1 \mathrm{v} / \mathrm{v} / \mathrm{v})$. Soil used in the experiment was collected from Pailou experimental station of Nanjing Agricultural University $\left(118.78^{\circ} \mathrm{E}, 22.04^{\circ} \mathrm{N}\right)$. The characteristics of the soil were measured, which contained $5.60 \%$ soil water content, $7.70 \mathrm{~g} / \mathrm{kg}$ soil organic $\mathrm{C}, 18.49 \mathrm{mg} / \mathrm{kg}$ available $\mathrm{P}, 36.24 \mathrm{mg} / \mathrm{kg}$ nitrate $\left(\mathrm{NO}_{3}{ }^{-}\right), 19.61 \mathrm{mg} / \mathrm{kg}$ ammonium $\left(\mathrm{NH}_{4}{ }^{+}\right), 0.83 \mathrm{~g} / \mathrm{kg}$ total nitrogen and $\mathrm{pH}$ of 7.42 .

The five AMF species used were Claroideoglomus etunicatum, Glomus tortuosum, Rhizophagus intraradices,G. versiforme,G. aggregatum. Soil inoculation with AMF strains purchased from Beijing Academy of Agriculture and Forestry, China. AMF spores contained in soil inoculation were propagated in autoclaved $\left(121^{\circ} \mathrm{C}\right.$ for $\left.120 \mathrm{~min}\right)$ substrate $(\mathrm{sand} / \mathrm{soil}, 1: 2)$ with maize for two successive propagation cycles (three months for each cycle). The soil of five 
105 AMF species were mixed as inoculants with spore density of $48 / \mathrm{g}$.

106 AMF inoculation and plant growth conditions

107

108

109

110

111

112

113

114

115

116

117

118

119

120

121

122

123

124

125

In microcosms without root interaction, each plant growth pillar received $6 \mathrm{~g}$ of AMF inoculants for $+\mathrm{AMF}$ treatment and $6 \mathrm{~g}$ of autoclaved inoculants $\left(121^{\circ} \mathrm{C}\right.$ for $\left.120 \mathrm{~min}\right)$ for $-\mathrm{AMF}$ treatment. In microcosms with root interaction, the soil mixture in the growth space between the container and root restriction pillar was inoculated with 48-g AMF inoculum for +AMF treatment and 48 -g autoclaved inoculants $\left(121^{\circ} \mathrm{C}\right.$ for $\left.120 \mathrm{~min}\right)$ for $-\mathrm{AMF}$ treatment. To compensate other lost soil microbe because of sterilization, $80 \mathrm{ml}$ filtrate from fresh field soil mud excluding AMF by $25 \mu \mathrm{m}$ mesh was applied to each microcosm. Because the root of T.repens is easily colonized by rhizobium in the field, $24 \mathrm{ml}\left(\mathrm{OD}_{600}=0.90\right)$ mixed rhizobium inoculants (Rhizobium sp. WYCCWR R10051 and Rhizobium sp. WYCCWR R10062) isolated from $T$. repens was added to each microcosm. Rhizobium inoculants were kindly provided by Dr. Zhang Junjie in Zhengzhou University of Light Industry (Zhang et al. 2016).

We used commercial seeds of T. repens (Trade name: Haifa) and L. perenne (Trade name: Maidi). The two varieties were widely used in south of China for pasture cultivation. The seeds were sterilized with $10 \% \mathrm{H}_{2} \mathrm{O}_{2}$ for $10 \mathrm{~min}$, washed with sterilized water and germinated in wet filter paper in lighting incubator $\left(20^{\circ} \mathrm{C}\right)$ for 2-4 days. And then seedlings were transplanted into each microcosms. Three seedlings of $T$. repens or $L$. perenne were transplanted to each plant growth pillar in the microcosms without root interaction. We alternated $T$. repens with $L$. perenne in the T4L4 treatment. Three seedlings of $T$. repens or L. perenne were randomly located in one growth pillar and another three seedlings of $T$. repens or $L$. perenne were 
126

127

128

129

130

131

132

133

134

135

136

transplanted into the opposite pillar in T2L6 or T6L2 treatment, respectively. Seedlings of $T$.

repens or L. perenne were spaced in the same way in microcosms with root interaction.

The seedlings were grown under glasshouse conditions at $50-70 \%$ relative humidity, a temperature regime of $20-25^{\circ} \mathrm{C}$ during day and night and natural lighting. Each microcosm was watered weekly, and soil water content was corrected to $15.4 \%$ (field capacity) every two weeks. One week later, the strongest seedlings were left and the other two were removed from each pillar of the microcosms without root interaction and the corresponding location in microcosms with root interaction. We randomized the location of all microcosms every two weeks.

\section{Harvesting and measurements}

Shoots were harvested 9, 13 and 16 weeks after planting to simulate mowing/grazing and reduce possible shoot competition for light. We failed to determine nitrogen transfer among plant individuals because of technical problems. Samples in these microcosms were added to each harvest. At the time of harvest at 9 and 13 weeks, shoots were mowed to $5 \mathrm{~cm}$ height, sorted by species, oven dried at $65^{\circ} \mathrm{C}$ for $72 \mathrm{~h}$ and weighed. During the final harvest all plants were destructively harvested, separated into shoots and roots and sorted by species. Roots of one plant individual of $T$. repens or $L$. perenne in each microcosm were frozen at $-20^{\circ} \mathrm{C}$ for determining AMF root colonization. Shoots and the left roots were oven dried at $65^{\circ} \mathrm{C}$ for $72 \mathrm{~h}$ and weighed. We estimated the shoot dry matter for each species by pooling the three harvests. We assumed that plant individual of the same species in each microcosm had the same root dry matter. Thus, the dry matter value for roots used for determining colonization was estimated by the average root biomass of the same species. Shoot $\mathrm{N}$ content was examined using alkaline-hydrolysable 
147 diffusion method with Kjeldahl apparatus (Kjeltec Analyzer Unit 8400, FOSS, Hillerod, Sweden)

148 (Bremner et al. 1996). Shoot P content was measured using an inductively coupled plasma

149 emission spectrometer (Iris Advantage 1000, USA), following digesting the plant tissue with trace-metal-grade nitric and perchloric acid and diluting in $100 \mathrm{~mL}$ of double-distilled water.

Frozen roots were cut into approximately $1-\mathrm{cm}$ fragments. The root samples were cleared in $10 \%(\mathrm{w} / \mathrm{v}) \mathrm{KOH}$ at $90{ }^{\circ} \mathrm{C}$ in a water bath for $60 \mathrm{~min}$, and then washed and stained with $0.05 \%$

(w/v) Trypan blue. Thirty root segments from each sample were examined microscopically to assess AMF root colonization (Trouvelot et al. 1986).

\section{Statistical analysis}

Competitive interactions between $T$. repens and L. perenne were calculated as the relative shoot biomass per individual $(\mathrm{RY}$ ind $)$ by the equation: $\mathrm{RY}$ ind $=O_{i j} / M_{i j}$, where $O_{i j}$ is the shoot biomass per individual of plant species $i$ grown in mixed planting microcosm of root interaction $\times$ AMF treatment combination species $j$, and $M_{i j}$ is the mean shoot biomass per individual of plant species $i$ grown in monoculture microcosm of root interaction $\times$ AMF treatment combination species $j$ (de Wit 1960, Wagg et al. 2011).

Relative yield totals (RYTs) were calculated by the equation: $\mathrm{RYTs}=\mathrm{RY} \mathrm{R}_{1}+\mathrm{RY}_{2}$, where $\mathrm{RY}_{1}$ or $\mathrm{RY}_{2}$ are shoot biomass of plant species 1 or 2 in mixture divided by the shoot biomass in the monoculture of root interaction $\times$ AMF treatment combination. We used RYTs to estimate overyielding in grass-clover mixtures. Values greater than 1 indicate overyielding that a greater biomass production was observed in mixtures than the average of the two species in monoculture (de Wit 1960, Wagg et al. 2011). 
A general linear model (GLM) was used to determine the effect of planting ratio, root

169

170

171

172

173

174

175

176

177

178

179

180

181

182

183

184

185

186

187

interaction and their interactions on AMF root colonization in the +AMF treatment. GLM was also applied to analyze the effects of AMF inoculation, planting ratio, root interaction and their interactions on shoot and root biomass, $\mathrm{RY}_{\text {ind }}, \mathrm{RYT}$, shoot $\mathrm{N}$ and $\mathrm{P}$ content. AMF inoculation, planting ratio and root interaction were treated as the fixed factors in these analyses. The data were log-transformed prior to analysis to ensure normality and homogeneity by using shapirowilk test.

As AMF inoculation and its interaction with other factors did not significantly alter any measurements (Table S1-S3), +AMF and -AMF were treated as replicates in the following analysis. We used GLM to test the main factor of planting ratio, root interaction and their interaction on each measurement. Tukey's simultaneous test were used to compare the variations between + Root and - Root treatment, and the level of significance was $P<0.05$. LSD multiplerange test was applied to analyses the least significance differences among planting ratio treatments. All statistical analyses were performed using SAS Version 8.0 (SAS Institute Inc., Cary, NC, USA), and all figures were made by using Sigma plot 12.0 (Systat Software Inc., San Jose, CA, USA).

\section{Results}

\section{AMF inoculation effect}

AMF inoculation and its interaction with other factors did not significantly alter any measurements in our study (all $p>0.05$; Table S1-S3). The average mycorrhizal root colonization was less than $0.5 \%$ in the -AMF treatment, while AMF successfully colonized both 
189 T. repens and L. perenne in the + AMF treatment by $39 \%$ and $21 \%$, respectively. As Fig. S1

190 shown, mycorrhizal root colonization of $T$. repens was not affected by either root interaction,

191 planting ratio or their interactions $(p>0.05)$. Mycorrhizal root colonization of $L$. perenne was

192 affected by planting ratio $(p<0.001)$. Mycorrhizal root colonization of $L$. perenne increased

193 significantly along with the increasing proportion of T. repens in mixtures.

194 Above- and belowground biomass of $T$. repens and L. perenne

195 The aboveground biomass of $T$. repens and L. perenne were all significantly affected by root interaction, planting ratio and their interactions, as well as belowground biomass $(p<0.05$; Fig.

2). The exception was total aboveground biomass, which was not affected by root interaction ( $p$

$>0.05)$. When the planting ratios ranged from T2:L6 to T4:L4 and T6:L2, the aboveground

biomass of T.repens with root interaction respectively decreased from $47 \%, 46 \%$ to $42 \%$ in comparison with no root interaction (Tukey's simultaneous test, $p<0.05$; Fig. 2a). The aboveground biomass of $L$. perenne increased by $10 \%$ and $30 \%$ at the planting ratio of T4L 4 and

T6L2 (Tukey's simultaneous test, $p<0.05$ ) and did not alter aboveground biomass in

monoculture and the planting ratio of T2L6 (Tukey's simultaneous test, $p>0.05$; Fig. 2b). Root

interaction significantly decreased total aboveground biomass at the planting ratio of T4L4 and

T8L0 (Tukey's simultaneous test, $p<0.05$; Fig. 2c). Total aboveground biomass peaked at the planting ratio of T4L4 (Fig. 2c).

The belowground biomass of $T$. repens decreased with root interaction in the mixed planting

208 (Tukey's simultaneous test, $p<0.05$; Fig. 2d), which was similar to the responses of aboveground biomass (Fig. 2a). In monoculture, though the presence of root interaction 
210 increased belowground biomass of $T$. repens by $21 \%$ (Tukey's simultaneous test, $p<0.05$; Fig.

$2112 \mathrm{~d}$ ), the aboveground biomass of $T$. repens was decreased by 12\% (Tukey's simultaneous test, $p$

$212<0.05)$ with root interaction, indicating that the root interaction in intraspecies decreased the

213 aboveground biomass of $T$. repens. In contrast, the belowground biomass of L. perenne

214 significantly increased with root interaction in the mixed planting (Tukey's simultaneous test, $p$

$215<0.05$; Fig. 2e). In monoculture, the presence of root interaction increased belowground biomass

216 of L. perenne by $64 \%$ (Tukey's simultaneous test, $p<0.05$; Fig. 2e), while the aboveground

217 biomass of L. perenne was not altered with root interaction (Fig. 2b), indicating that the

218 intraspecific root interaction did not affect the aboveground biomass of L. perenne. Root

219 interaction significantly increased total aboveground biomass at the planting ratio of T0L8 and

220 T2L6 (Tukey's simultaneous test, $p<0.05$; Fig. 2f)

\section{Relative yields}

222 The relative yield per individual $\left(\mathrm{RY}_{\mathrm{ind}}\right)$ of $T$. repens and L. perenne were strongly influenced

223 by root interaction, planting ratio and their interactions (Tukey's simultaneous test, all $p<0.05$;

224 Fig. 3 a and b). In mixtures with L. perenne, the $\mathrm{RY}_{\text {ind }}$ of T. repens was depressed below its

$225 \mathrm{RY}_{\text {ind }}$ in monoculture by $27 \%$ in the absence of root interaction (Fig. 3a). The presence of root

226 interaction reduced the $\mathrm{RY}_{\text {ind }}$ of $T$. repens by 54\% compared with that in monoculture (Fig. 3a),

227 suggesting that competitive pressure by L. perenne root decrease the growth performance of $T$. 228 repens.

229 In mixtures with $T$. repens, the $\mathrm{RY}_{\text {ind }}$ of $L$. perenne was promoted above its $\mathrm{RY}$ ind in 230 monoculture by $65 \%$ on average in the absence of root interaction (Fig. 3b). The presence of root 
231

232

interaction largely enhanced the $\mathrm{RY}_{\text {ind }}$ of $L$. perenne by $101 \%$ on average compared with that in monoculture (Fig. 3b), suggesting that $L$. perenne benefited from interspecies root interaction. In addition, the $\mathrm{RY}_{\text {ind }}$ of $L$. perenne increased along with the proportion of $T$. repens in mixture $(p<$ 0.0001; Fig. 3b). The positive effect of root interaction on the $R Y_{\text {ind }}$ of $L$. perenne was also raised with the increase in the proportion of $T$. repens in mixture (Root interaction $\times$ Planting ratio, $p<0.0001$; Fig. 3b). Planting ratio heavily affected the relative yield total (RYT) $(p<$ 0.0001; Fig. 4). RYT peaked at the 4:4 mixture of T. repens and L. perenne.

\section{$\mathbf{N}$ and $P$ content}

Shoot $\mathrm{N}$ content of $T$. repens were not affected by root interaction, planting ratio or their interactions (Table S3). Shoot $\mathrm{N}$ content of $L$. perenne significantly decreased when its planting ratio changed from monocultures to mixtures in any ratio with T. repens (LSD, $p<0.05$; Table 1). Shoot $\mathrm{P}$ content of both $T$. repens and $L$. perenne were not significantly altered by root interaction, planting ratio or their interactions (Table S3).

\section{Discussion}

Root interactions exert contrasting effects on T. repens and L. perenne. In mixture, the much higher yield of $L$. perenne suggests that it suppresses the growth of $T$. repens by interspecies root interactions. Overyielding in mixture is majorly contributed by the biomass of L perenne. Although legumes could offer extra $\mathrm{N}$ to grasses by using its specific fixed $\mathrm{N}$ (Louarn et al. 2015, Thilakarathna et al. 2016), which should enhance the competitive ability of grasses, our result indicated that there was competition between $T$. repens and $L$. perenne as a lower $\mathrm{N} \%$ of $L$. perenne was observed in polyculture (table 1). Since planting ratio strongly affected the relative 
252 yield total, it is very crucial to select reasonable scale for optimizing mixed sowing pasture and

253 agricultural intercropping system.

254 We failed to detect significant effects of AMF inoculation on shoot or root biomass of both 255 species. This is consistent with the result from Endlweber and Scheu (2007)'s study. However, 256 AMF inoculation reduced the competitive inequality between $T$. pratense and L. multiflorum by 257 reducing the growth suppression of the legume by the grass (Wagg et al. 2011). It may attribute 258 to the fertile soil condition. AMF inoculation has been shown to result in greater effects on the 259 plant growth response in the less productive soil and can suppress plant growth in high $\mathrm{P}$ soil 260 (Johnson 2010, Wagg et al. 2011, Johnson et al. 2015).

261 No matter with or without root interaction, the mixtures of $T$. repens and L. perenne had no 262 significant difference with the monocultures in regard to AMF colonization root of T. repens. 263 However, L. perenne showed a higher AMF colonization in mixtures than in its monoculture, 264 and increased mycorrhizal root colonization significantly along with the increased proportion of 265 T. repens in mixtures, which is similar to competitive ability of $L$. perenne across planting ratios 266 (Fig. 3b). These indicate that legume and grass mixed sowing grassland could enhance grasses' 267 AMF colonization and it was related to plant competition.

268 Extraradical hyphae of AMF affect interspecific competition with root interaction in mixtures 269 by mediating resource competition (Janouskova et al. 2011, Wagg et al. 2011, Jiang et al. 2017).

270 When comparing the legume $T$. repens and the grass $L$. perenne, our results showed that $T$. 271 repens had twofold higher AMF colonization than L. perenne, which may result in a higher $\mathrm{N}$ 272 benefit from AMF for legume species than grasses. As AMF contributes to plant $\mathrm{N}$ variation 
273 widely (Hodge and Storer 2015), plant N content of L. perenne significantly decreased from 274 monocultures to mixtures in any ratio with $T$. repens suggesting that this extra $\mathrm{N}$ conferred a 275 competitive advantage to $T$. repens, and it is also likely that competition for $\mathrm{N}$ between 276 symbionts occurs. Legume T. repens presented a higher $\mathrm{N}$ content because of its widely known 277 N fixing capacity, resulting from its $\mathrm{N}$ fixing rhizobial symbionts. Besides, with root interaction, 278 the decreased belowground biomass of T. repens in mixtures in comparison with it increased in monocultures suggests that legume could better promote their nutrient absorbing by intraspecies root interaction rather than interspecies root interaction. Our findings showed that the total yield of mixtures decreased aboveground biomass majorly because of $T$. repens, and increased belowground biomass majorly because of $L$. perenne across planting ratios. Overyielding in mixtures was mainly due to the biomass of L. perenne. It indicates that L. perenne has much stronger root interaction than legume $T$. repens by producing more biomass. The previous study from Mouat et al. (1987) also confirms that the root competitive capacity of T. repens is restricted by the concentration and types of soil nutrients elements. Since plant species absorbing soil nutrient largely rely on their root system, the different root interaction of $T$. repens and $L$. perenne thus affect their variable aboveground biomass. Besides, the mechanism of overcompensatory growth could also verify their root competitive capacity. L. perenne performs overcompensatory growth by decreasing root biomass or its shoot: root ratio, but $T$. repens is dependent on enhancing photosynthetic efficiency or symplastic growth of the shoot and root together (Faurie et al. 1996, Akmal and Janssens 2004). The mixed sowing of T. repens and $L$. 
294 productivity in mixtures, and thus contributes to overyielding effect. It is worth mentioning that

295 the competitive capacity of $T$. repens and L. perenne change along with their growth periods

296 (Schenk et al. 1995, Coutts and Jones 2002). Although mixed sowing increase the yield of $L$.

perenne and decrease of the one from $T$. repens, their competitive capabilities change in an

inverse way and thus further enhance their compatibility (Elgersma et al. 2000, Nie et al. 2004).

Therefore, they could sustainably coexist in the long term.

300 Building productive and stable artificial grassland is a very important measure for meeting livestock - feeds balance (Zhou et al. 2006, Huang et al. 2017). Mixed sowing of legume $T$.

repens and grass L. perenne in half could effectively improve grassland production and forage

quality. Our results suggest that planting ratios is a key driver in modulating plant species

competitive power in mixtures through root interaction. Our findings provide better

understanding of the root interaction and nutrient usage capabilities of these two most important

forages, and have important implications for optimizing grassland measures according to the

characteristic of component species.

308

309

310

311

312

313

314

315

\section{Acknowledgements}

We are grateful to Hong Shen, Weiyang Gui, Bin Liu, Xiao Sun, Jihui Chen, Mohan Liu who helped in collecting and processing data. Many thanks are expressed to the anonymous reviewers for their helpful suggestions.

\section{References}

Akmal, M., and M. J. J. Janssens. 2004. Productivity and light use efficiency of perennial ryegrass with contrasting water and nitrogen supplies. Field Crops Research 88:143-155.

Bremner, J. B., R. J. Smith, and G. J. Tarrant. 1996. A Meisenheimer rearrangement approach to 
bridgehead hydroxylated tropane alkaloid derivatives. Tetrahedron Letters 37:97-100.

Brundrett, M. 2009. Mycorrhizal associations and other means of nutrition of vascular plants: understanding the global diversity of host plants by resolving conflicting information and developing reliable means of diagnosis. Plant and Soil 320:37-77.

Cernoch, V., and I. Houdek. 1994. Competitive ability of Kentucky bluegrass (Poa-pratensis. L) in simple mixtures with grasses and clovers Rostlinna Vyroba 40:193-204.

Coutts, B. A., and R. A. C. Jones. 2002. Temporal dynamics of spread of four viruses within mixed species perennial pastures. Annals of Applied Biology 140:37-52.

Davidson, I. A., and M. J. Robson. 1990. Short-term effects of nitrogen on the growth and nitrogen nutrition of small swards of white clover and perennial ryegrass in spring. Grass and Forage Science 45:413-421.

de Wit, C. T. 1960. On competition. Verslag Landbouwkundige Onderzoek 66:81-82.

del Río, M., H. Pretzsch, R. Ruíz-Peinado, E. Ampoorter, P. Annighöfer, I. Barbeito, K. Bielak, G. Brazaitis, L. Coll, L. Drössler, M. Fabrika, D. I. Forrester, M. Heym, V. Hurt, V. Kurylyak, M. Löf, F. Lombardi, E. Madrickiene, B. Matović, F. Mohren, R. Motta, J. den Ouden, M. Pach, Q. Ponette, G. Schütze, J. Skrzyszewski, V. Sramek, H. Sterba, D. Stojanović, M. Svoboda, T. M. Zlatanov, and A. Bravo-Oviedo. 2016. Species interactions increase the temporal stability of community productivity in Pinus sylvestrisFagus sylvatica mixtures across Europe. Journal of Ecology:n/a-n/a.

Dennis, W. D., and J. Woledge. 1987. The effect of nitrogen in spring on shoot number and leafarea of white clover in mixtures. Grass and Forage Science 42:265-269.

Elgersma, A., M. Nassiri, and H. Schlepers. 1998. Competition in perennial ryegrass white clover mixtures under cutting. 1. Dry-matter yield, species composition and nitrogen fixation. Grass and Forage Science 53:353-366.

Elgersma, A., and K. Søegaard. 2017. Changes in nutritive value and herbage yield during extended growth intervals in grass-legume mixtures: effects of species, maturity at harvest, and relationships between productivity and components of feed quality (in press). Grass and Forage Science:DOI: 10.1111/gfs. 12287.

Elgersma, A., H. Schlepers, and M. Nassiri. 2000. Interactions between perennial ryegrass (Lolium perenne L.) and white clover (Trifolium repens L.) under contrasting nitrogen availability: productivity, seasonal patterns of species composition, $\mathrm{N}-2$ fixation, $\mathrm{N}$ transfer and N recovery. Plant and Soil 221:281-299.

Endlweber, K., and S. Scheu. 2007. Interactions between mycorrhizal fungi and Collembola: effects on root structure of competing plant species. Biology and Fertility of Soils 43:741-749.

Faurie, O., J. F. Soussana, and H. Sinoquet. 1996. Radiation interception, partitioning and use in grass clover mixtures. Annals of Botany 77:35-45.

Hebeisen, T., A. Luscher, S. Zanetti, B. U. Fischer, U. A. Hartwig, M. Frehner, G. R. Hendrey, H. Blum, and J. Nosberger. 1997. Growth response of Trifolium repens L. and Lolium perenne $\mathrm{L}$. as monocultures and bi-species mixture to free air $\mathrm{CO}_{2}$ enrichment and management. Global Change Biology 3:149-160. 
357

Hodge, A., and K. Storer. 2015. Arbuscular mycorrhiza and nitrogen: implications for individual plants through to ecosystems. Plant and Soil 386:1-19.

Hooper, D. U., F. S. Chapin, J. J. Ewel, A. Hector, P. Inchausti, S. Lavorel, J. H. Lawton, D. M. Lodge, M. Loreau, S. Naeem, B. Schmid, H. Setala, A. J. Symstad, J. Vandermeer, and D. A. Wardle. 2005. Effects of biodiversity on ecosystem functioning: A consensus of current knowledge. Ecological Monographs 75:3-35.

Huang, W., E. Zwimpfer, M. R. Hervé, Z. Bont, and M. Erb. 2017. Neighborhood effects determine plant-herbivore interactions below ground. Journal of Ecology:n/a-n/a. . DOI: 10.1111/1365-2745.12805.

Janouskova, M., J. Rydlova, D. Puschel, J. Szakova, and M. Vosatka. 2011. Extraradical mycelium of arbuscular mycorrhizal fungi radiating from large plants depresses the growth of nearby seedlings in a nutrient deficient substrate. Mycorrhiza 21:641-650.

Jiang, J., J. A. M. Moore, A. Priyadarshi, and A. T. Classen. 2017. Plant-mycorrhizal interactions mediate plant community coexistence by altering resource demand. Ecology 98:187-197.

Johnson, N. C. 2010. Resource stoichiometry elucidates the structure and function of arbuscular mycorrhizas across scales. New Phytologist 185:631-647.

Johnson, N. C., G. W. T. Wilson, J. A. Wilson, R. M. Miller, and M. A. Bowker. 2015. Mycorrhizal phenotypes and the Law of the Minimum. New Phytologist 205:1473-1484.

Kleen, J., F. Taube, and M. Gierus. 2011. Agronomic performance and nutritive value of forage legumes in binary mixtures with perennial ryegrass under different defoliation systems. Journal of Agricultural Science 149:73-84.

Letten, A. D., P.-J. Ke, and T. Fukami. 2017. Linking modern coexistence theory and contemporary niche theory. Ecological Monographs 87:161-177.

Li, B., Y.-Y. Li, H.-M. Wu, F.-F. Zhang, C.-J. Li, X.-X. Li, H. Lambers, and L. Li. 2016. Root exudates drive interspecific facilitation by enhancing nodulation and $\mathrm{N} 2$ fixation. Proceedings of the National Academy of Sciences 113:6496-6501.

Loreau, M., and A. Hector. 2001. Partitioning selection and complementarity in biodiversity experiments. Nature 412:72-76.

Louarn, G., E. Pereira-Lopès, J. Fustec, B. Mary, A.-S. Voisin, P. de Faccio Carvalho, and F. Gastal. 2015. The amounts and dynamics of nitrogen transfer to grasses differ in alfalfa and white clover-based grass-legume mixtures as a result of rooting strategies and rhizodeposit quality. Plant and Soil 389:289-305.

Luescher, A., and P. Jacquard. 1991. Coevolution between interspecific plant competitors. Trends in Ecology \& Evolution 6:355-358.

Mouat, M. C. H., M. J. M. Hay, J. R. Crush, P. Nes, J. Dunlop, and A. L. Hart. 1987. Effects of nitrogen and phosphorus applications on pasture growth and composition on a recent alluvial soil with low phosphorus retention. New Zealand Journal of Experimental Agriculture 15:143-146.

Nassiri, M., and A. Elgersma. 1998. Competition in perennial ryegrass white clover mixtures under cutting. 2. Leaf characteristics, light interception and dry-matter during regrowth. Grass and Forage Science 53:367-379. 
Nie, Z. N., D. F. Chapman, J. Tharmaraj, and R. Clements. 2004. Effects of pasture species mixture, management, and environment on the productivity and persistence of dairy pastures in south-west Victoria. 2. Plant population density and persistence. Australian Journal of Agricultural Research 55:637-643.

Nyfeler, D., O. Huguenin-Elie, M. Suter, E. Frossard, J. Connolly, and A. Luscher. 2009. Strong mixture effects among four species in fertilized agricultural grassland led to persistent and consistent transgressive overyielding. Journal of Applied Ecology 46:683-691.

Sanderson, M. A., G. Brink, R. Stout, and L. Ruth. 2013. Grass-legume proportions in forage seed mixtures and effects on herbage yield and weed abundance. Agronomy Journal 105:1289-1297.

Schenk, U., R. Manderscheid, J. Hugen, and H. J. Weigel. 1995. Effects of CO2 enrichment and intraspecific ocmpetiton on biomass partitioning, nitrogen content and microbial biomass carbon in soil of perennial ryegrass and white clover. Journal of Experimental Botany 46:987-993.

Schwinning, S., and A. J. Parsons. 1996. Analysis of the coexistence mechanisms for grasses and legumes in grazing systems. Journal of Ecology 84:799-813.

Smith, S. E., and D. J. Read. 2008. Mycorrhizal Symbiosis (3rd edition). Elsevier, New York.

Thilakarathna, M. S., M. S. McElroy, T. Chapagain, Y. A. Papadopoulos, and M. N. Raizada. 2016. Belowground nitrogen transfer from legumes to non-legumes under managed herbaceous cropping systems. A review. Agronomy for Sustainable Development 36.

Trouvelot, A., J. L. Kough, and V. Gianinazzi-Pearson. 1986. Mesure du taux de mycorhization VA d'un système radiculaire. Recherche de méthodes d'estimation ayant une signification fonctionnelle. Pages 217-221 in V. Gianinazzi-Pearson and S. Gianinazzi, editors. Physiological and Genetic Aspects of Mycorrhizae. INRA, Paris.

Ulrich, W., F. Jabot, and N. J. Gotelli. 2017. Competitive interactions change the pattern of species co-occurrences under neutral dispersal. Oikos 126:91-100.

Wagg, C., J. Jansa, M. Stadler, B. Schmid, and M. G. A. van der Heijden. 2011. Mycorrhizal fungal identity and diversity relaxes plant-plant competition. Ecology 92:1303-1313.

Wang, G. Z., H. G. Li, P. Christie, F. S. Zhang, J. L. Zhang, and J. D. Bever. 2017. Plant-soil feedback contributes to intercropping overyielding by reducing the negative effect of take-all on wheat and compensating the growth of faba bean. Plant and Soil 415:1-12.

Zhang, J. J., X. Y. Jing, P. de Lajudie, C. Ma, P. X. He, R. P. Singh, W. F. Chen, and E. T. Wang. 2016. Association of white clover (Trifolium repens L.) with rhizobia of sv. trifolii belonging to three genomic species in alkaline soils in North and East China. Plant and Soil 407:417-427.

Zhou, Z., O. J. Sun, J. Huang, Y. Gao, and X. Han. 2006. Land use affects the relationship between species diversity and productivity at the local scale in a semi-arid steppe ecosystem. Functional Ecology 20:753-762. 


\section{Figure 1 (on next page)}

Conceptual diagram illustrating microcosms without and with root interaction.

(a) Microcosm without root interaction containing eight plant growth pillars $(13 \mathrm{~cm}$ in height and $4 \mathrm{~cm}$ in diameter). There was no root interaction among plants as each plant individual was grown in pillar made of 25- $\mu \mathrm{m}$ nylon mesh, which allow arbuscular mycorrhizal (AM) mycelia access but not roots. Each pillar contained soil mixture of $188 \mathrm{~g}$ and one plant individual. (b) Microcosm with root interaction containing one root restriction pillar. Plant individuals were planted in the space between the container and root restriction pillar, which contained soil mixture of $1504 \mathrm{~g}$ (188 $\mathrm{g} * 8$ ) and eight plant individuals. Root restriction pillar made of 25- $\mu \mathrm{m}$ nylon mesh allowed AM mycelia access but not roots. T hus, to ensure the homogeneity, the total growth space for root in (a) was same as in (b) , by calculating the total soil mixture of eight plant growth pillars in (a) and then setting the same size pillar in (b). 


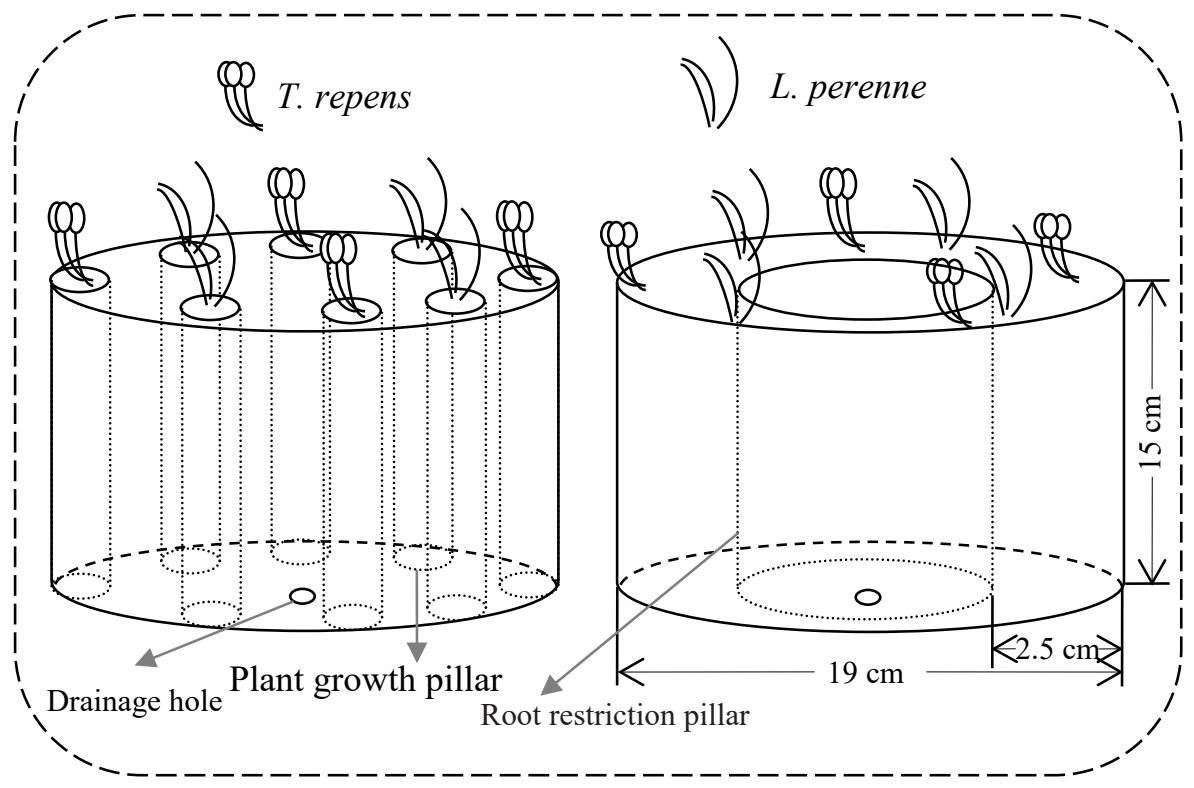

(a) Without root interaction

(b) With root interaction 
Figure 2

Effects of root interaction ( $R$ ), planting ratio (Ratio) and their interactions ( $R \times$ Ratio) on above- and belowground biomass of $T$. repens ( $a$ and $d$ ), L. perenne ( $b$ and $e$ ) and the total (e and f).

T8L0, T6L2, T 4L4, T2L6, T0L8 mean planting ratio of $T$. repens and $L$.perenne: 8:0, 6:2, 4:4, 2:6, 0:8, respectively. Bar groups with \# indicate significant $(P<0.05)$ differences between + Root and -Root treatments. ${ }^{* * *} P<0.001 ; * * P<0.01 ; * P<0.05 ;$ ns $P>0.05$
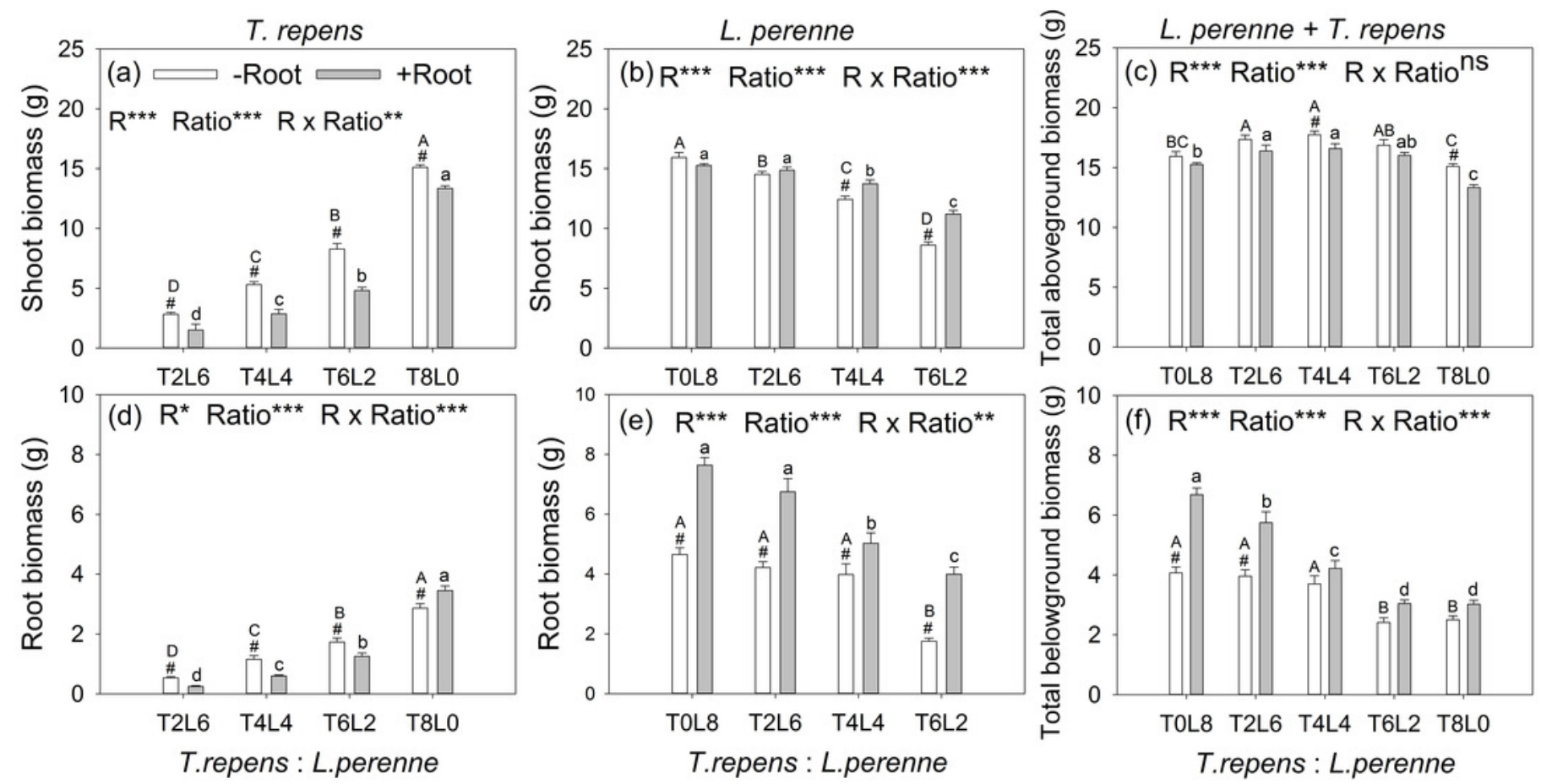
Figure 3 (on next page)

Effects of root interaction ( $R$ ), planting ratio (Ratio) and their interactions $(R \times$ Ratio) on relative yield per individual $\left(\mathrm{RY}_{\text {ind }}\right)$ of T.repens (a) and L.perenne (b).

T8L0, T6L2, T4L4, T2L6, T0L8 mean planting ratio of $T$. repens and $L$. perenne: 8:0, 6:2, 4:4, 2:6, 0:8, respectively. Data are means $\pm \mathrm{SE}$. ${ }^{* * *} P<0.001 ; * P<0.05$ 

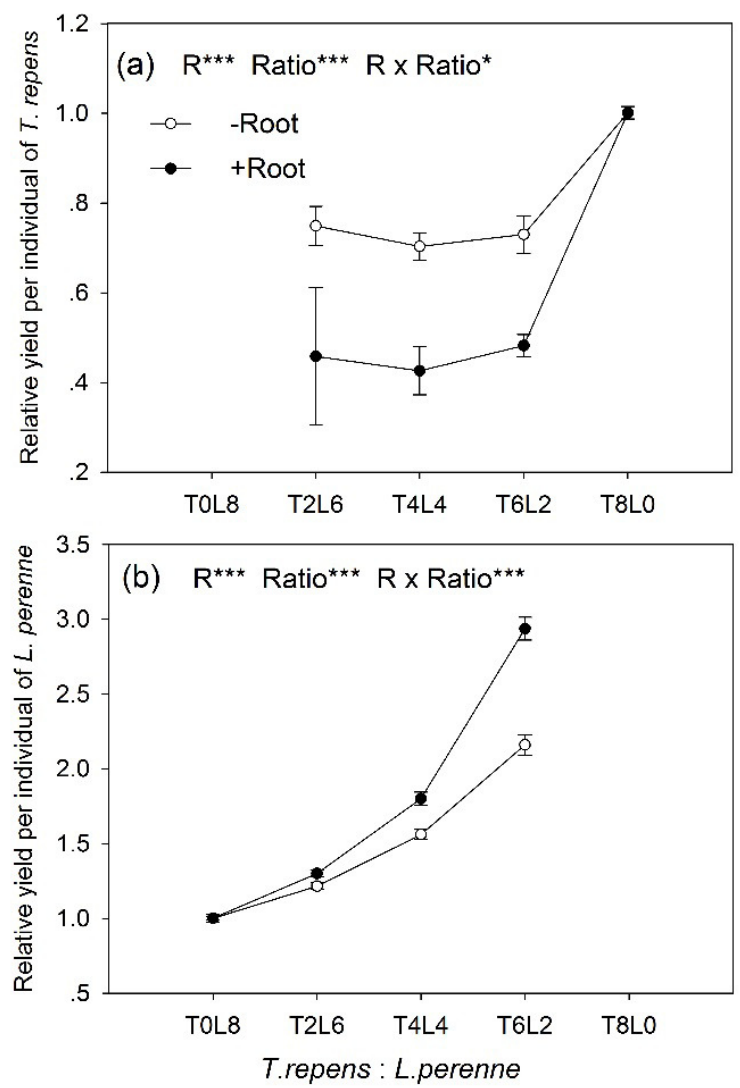
Figure 4(on next page)

Effects of root interaction ( $R$ ), planting ratio (Ratio) and their interactions $(R \times$ Ratio) on the relative yield total.

T8L0, T6L2, T4L4, T2L6, T0L8 mean planting ratio of $T$. repens and $L$. perenne: 8:0, 6:2, 4:4, $2: 6,0: 8$, respectively. Data are means $\pm \mathrm{SE}$. $* * * P<0.001 ; \mathrm{ns} P>0.05$ 


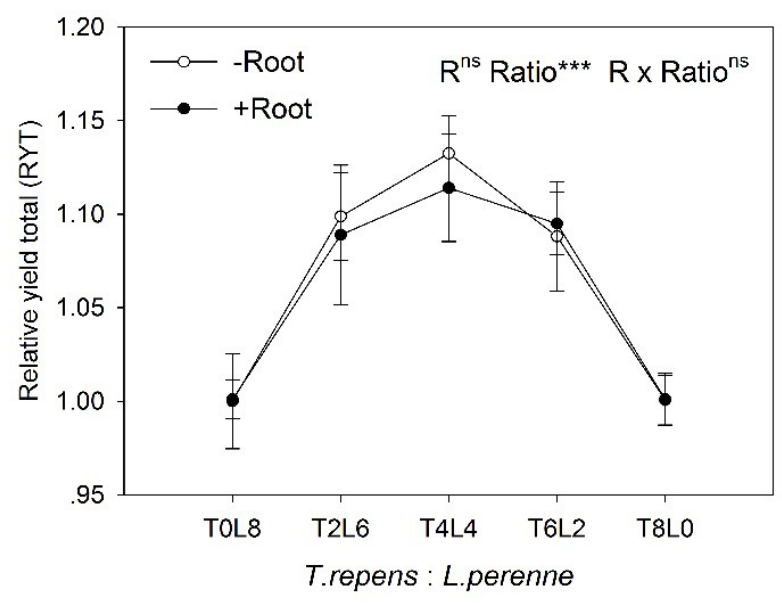




\section{Table $\mathbf{1}$ (on next page)}

Planting ratio effects on $\mathrm{N}$ and $\mathrm{P}$ content of T.repens and L.perenne (Mean $\pm \mathrm{SE}$ ).

Different uppercases represent significant differences among planting ratio of T.repens $(T)$ and L.perenne (L) (LSD multiple-range tests, $P<0.05)$. T8L0, T6L2, T4L4, T2L6, T0L8 mean planting ratio: 8:0, 6:2, 4:4, 2:6, 0:8, respectively. 
1 Table 1 Planting ratio effects on $\mathrm{N}$ and $\mathrm{P}$ content of T.repens and L.perenne (Mean $\pm \mathrm{SE}$ ).

2

\begin{tabular}{cccccc}
\hline & \multicolumn{2}{c}{ T. repens } & & \multicolumn{2}{c}{ L. perenne } \\
\cline { 2 - 3 } \cline { 5 - 6 } \cline { 5 - 6 } T0L8 & $\mathrm{P} \%$ & & $\mathrm{~N} \%$ & $\mathrm{P} \%$ \\
\hline T2L6 & $3.49 \pm 0.10$ & $0.70 \pm 0.11$ & & $2.15 \pm 0.12 \mathrm{~B}$ & $0.49 \pm 0.04$ \\
T4L4 & $3.55 \pm 0.11$ & $0.72 \pm 0.06$ & & $2.13 \pm 0.13 \mathrm{~B}$ & $0.50 \pm 0.05$ \\
T6L4 & $3.54 \pm 0.10$ & $0.58 \pm 0.05$ & & $2.41 \pm 0.13 \mathrm{~B}$ & $0.52 \pm 0.03$ \\
T8L0 & $3.39 \pm 0.11$ & $0.49 \pm 0.06$ & & & \\
\hline
\end{tabular}

3 Note: Different uppercases represent significant differences among planting ratio of T.repens (T)

4 and L.perenne (L) (LSD multiple-range tests, $P<0.05$ ). T8L0, T6L2, T4L4, T2L6, T0L8 mean

5 planting ratio: $8: 0,6: 2,4: 4,2: 6,0: 8$, respectively.

6 